
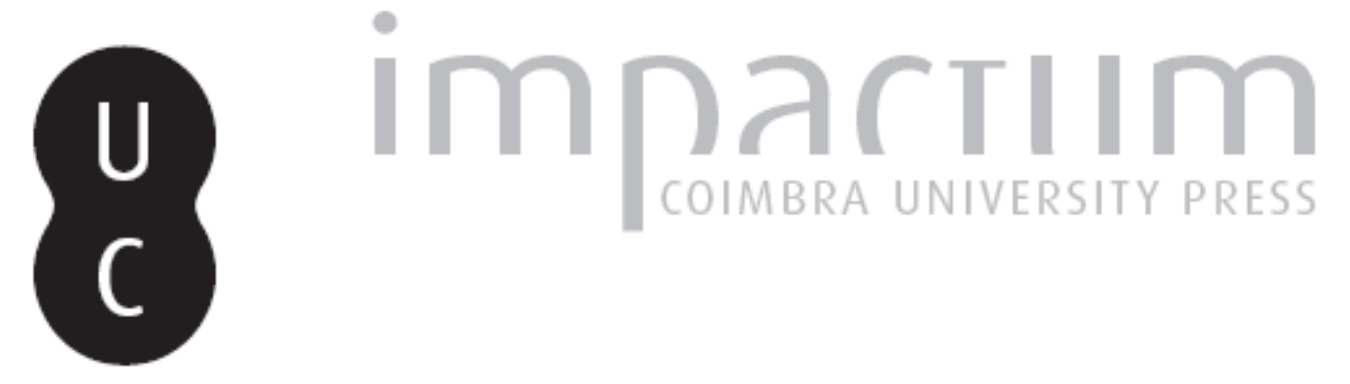

\title{
Os Filmes (D)escritos de Ana Teresa Pereira: Nightmare, de Alfred Hitchcock, e The Double, de David Cronenberg
}

\author{
Autor(es): $\quad$ Reis, Amândio Pereira \\ Publicado por: Centro de Literatura Portuguesa \\ URL \\ persistente: \\ URI:http://hdl.handle.net/10316.2/30061 \\ DOI: \\ DOI:http://dx.doi.org/10.14195/2182-8830_1-2_2
}

Accessed : $\quad$ 26-Apr-2023 11:15:43

A navegação consulta e descarregamento dos títulos inseridos nas Bibliotecas Digitais UC Digitalis, UC Pombalina e UC Impactum, pressupõem a aceitação plena e sem reservas dos Termos e Condições de Uso destas Bibliotecas Digitais, disponíveis em https://digitalis.uc.pt/pt-pt/termos.

Conforme exposto nos referidos Termos e Condições de Uso, o descarregamento de títulos de acesso restrito requer uma licença válida de autorização devendo o utilizador aceder ao(s) documento(s) a partir de um endereço de IP da instituição detentora da supramencionada licença.

Ao utilizador é apenas permitido o descarregamento para uso pessoal, pelo que o emprego do(s) título(s) descarregado(s) para outro fim, designadamente comercial, carece de autorização do respetivo autor ou editor da obra.

Na medida em que todas as obras da UC Digitalis se encontram protegidas pelo Código do Direito de Autor e Direitos Conexos e demais legislação aplicável, toda a cópia, parcial ou total, deste documento, nos casos em que é legalmente admitida, deverá conter ou fazer-se acompanhar por este aviso.

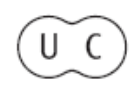




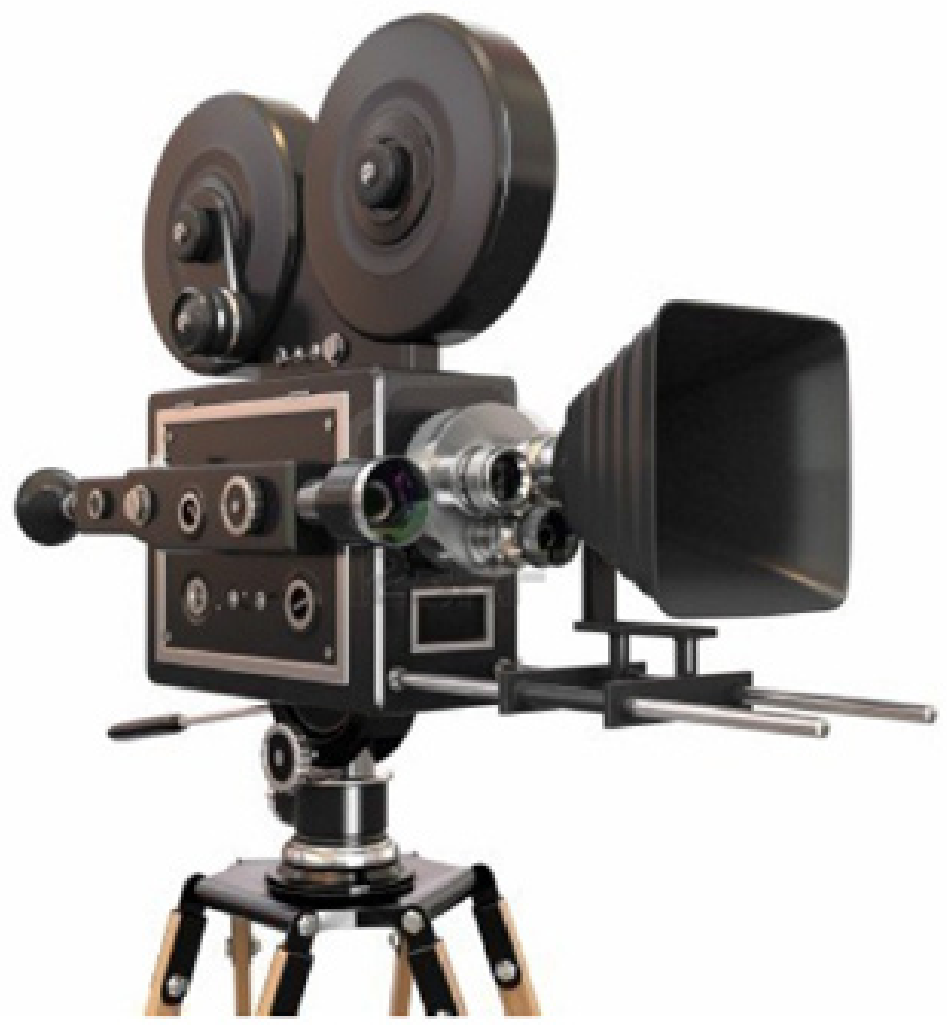

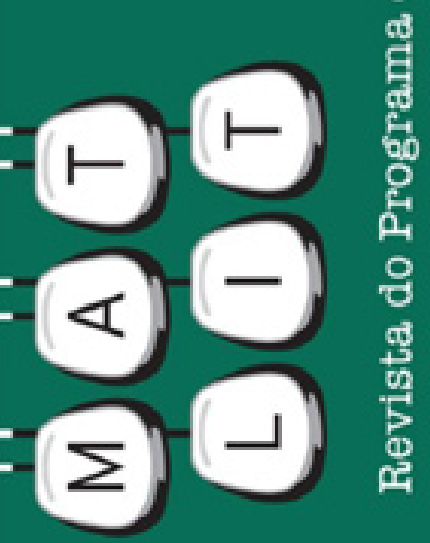

Vol. 1.2 (2013)

ISSN 2182-8830

'Escrita e Cinema'

Osvaldo Manuel Silvestre

\& Clara Rowland (orgs.) 


\title{
Os Filmes (D)escritos de Ana Teresa Pereira: Nightmare, de Alfred Hitchcock, e The Double, de David Cronenberg AMÂNDIO PEREIRA REIS
}

\author{
Universidade de Lisboa
}

\begin{abstract}
Resumo
A partir de uma comparação inicial com um texto ecfrástico de Calístrato (séc. III), e apoiando-nos em seguida em vários estudos sobre a écfrase como prática literária, desde a Antiguidade até ao presente, e até à sua aceitação enquanto género literário intermedial, é nosso objetivo refletir sobre dois contos particulares de Ana Teresa Pereira que encenam a apresentação de filmes inexistentes de Hitchcock e Cronenberg. Para tal, passaremos tanto por um leque de problemas associados à descrição ecfrástica - tais como a dialética entre realidade e ficção, verdade e falsidade, e imaginação e leitura - e às (im)possibilidades da representação por palavras e/ou imagens, como por um conjunto de questões levantadas pela específica relação transmedial que os textos de A. T. Pereira estabelecem entre a Literatura e o Cinema. Atentaremos ainda ao conceito de "filme escrito" de Pavle Levi como uma hipótese, entre outras, de identificação genológica destas narrativas. Palavras-chave: Écfrase; Literatura e Cinema; Intermédia; Pós-modernismo; Written Film.
\end{abstract}

\section{Abstract}

Starting with a comparative reading of an ekphrastic text by Callistratus (3rd century $\mathrm{AD})$ and taking support from various studies on ekphrasis as a literary practice, from antiquity to present times until its acceptance as an intermedial literary genre, it is our goal to analyze two short stories by Ana Teresa Pereira which invent non-existent films by Hitchcock and Cronenberg. Therefore, we will have to confront a range of problems associated with ekphrastic description - the dialectic between reality and fiction; truth and falsity; imagination and reading - and with the (im)possibilities of representation through image and/or words, including a set of questions posed by the specific transmedial relation that A. T. Pereira's texts establish between Literature and Cinema. We will also take into account the concept of Pavle Levi's "written film" as one possibility, among others, of a genre identification for these narratives. Keywords: Ekphrasis; Literature and Cinema; Intermedia; Postmodernism; Written Film. 


\section{1. Écfrase e falsa fictio}

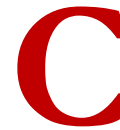

omeçamos esta reflexão com a tese inicial de um texto de Calístrato, escritor grego do fim do século III e autor de uma única obra, (Statuarum) descriptiones, menos conhecida pela designação grega Ekphraseis [Écfrases]. O texto é o segundo de um conjunto de catorze e intitula-se "Da estátua de uma bacante":

Não é apenas o trabalho dos poetas e dos escritores de prosa que se vê inspirado quando o divino poder dos deuses cai sobre as suas línguas. Não! Também as mãos de escultores, quando tomadas pelo dom de uma inspiração mais divina, dão expressão a criações que são possuídas e cheias de delírio. Assim Escopas, como que movido por certa inspiração, transmitiu à produção desta estátua o mesmo furor divino que havia dentro de si. Por que não descrever-vos eu, desde o princípio, a inspiração desta obra de arte? ${ }^{1}$

Antes de qualquer ponderação sobre o passo supracitado, apresentamos excertos também introdutórios de dois textos de Ana Teresa Pereira, autora portuguesa que começou a publicar em 1989 com a novela premiada, pretensamente policial, Matar a Imagem (Caminho, Col. Policial). Refiro-me aos contos "O ponto de vista das gaivotas", coligido na antologia Fairy Tales, originalmente publicada pela Black Sun Editores em 1996, e "She Who Whispers", publicado no ano seguinte, pela Relógio d’Água, na dupla antologia A Coisa Que Eu Sou, a qual reúne num só volume "Fairy Tales" e outro conjunto de contos até então inéditos, entre os quais este figura, a que se chamou "Ghost Stories".

O primeiro inicia com a seguinte exposição:

Segundo Orson Welles, "o que conta é a poesia”.

Lembro-me dessa frase a propósito de um filme pouco conhecido de Alfred Hitchcock: Nightmare de 1947.

$\mathrm{Na}$ filmografia do autor, o filme segue-se a Notorious e antecede The Paradine Case. Foi a única vez que ele dirigiu Humphrey Bogart (no mesmo ano em que ele protagonizou Dead Reckoning, The Two Mrs Carrolls e Dark Passage). (Pereira, 1997: 138)

${ }^{1}$ Tradução nossa. Na edição inglesa consultada: "It is not the art of poets and writers of prose alone that is inspired when divine power from the gods falls on their tongues, nay, the hands of sculptors also, when they are seized by the gift of a more divine inspiration, give utterance to creations that are possessed and full of madness. So Scopas, moved as it were by some inspiration, imparted to the production of this statue the divine frenzy within him. Why should I not describe to you from the beginning the inspiration of this work of art?” (Callistratus, 1981: 381; 2, \$1). 
No segundo caso, lê-se:

Depois de Videodrome (“a very heavy experience”) Cronenberg não quis escrever um novo guião; precisava de trabalhar material de outra pessoa enquanto recuperava as forças. Assim, filmou The Dead Zone [...].

Enquanto duravam as conversações com Dino de Laurentiis para as filmagens de Total Recall (que se frustraram [...]), Cronenberg realizou um filme de baixo orçamento, The Double (1985), baseado num conto escrito por ele mesmo quando estava na universidade [...]. (55)

A justaposição comparativa dos textos de Calístrato e de Ana Teresa Pereira pode parecer uma deriva inesperada - ou mesmo completamente imprópria -, mas cumpre aqui dois objetivos principais: sublinhar o fosso epocal, histórico e cultural que os separa, e evidenciar, não obstante, uma atitude ou uma intenção poética comum a ambos, assim como vários e específicos aspetos formais da sua composição que podem conduzir a um pensamento sobre a literatura enquanto meio de representação entre outros meios - mediador num "jeu de miroirs" (Hadot in Philostrate, 1991: vii e passim) - e sobre a história de um ou mais géneros literários, a sua prevalência e as suas possibilidades 'trans-históricas' e interdisciplinares, acabando por aproximá-los substancialmente.

Pondo por ora de parte a significativa asserção de Calístrato acerca de uma igual origem divina da inspiração em artes diferentes, a 'literatura' e a escultura, o que os dois autores se propõem fazer - ainda que a proposta de Ana Teresa Pereira permaneça absolutamente implícita - é oferecer-nos a descrição e a leitura/reconstrução crítica subjetiva (ou, em termos pessoanos, subjetivada) de um determinado objeto artístico, exterior aos seus textos e supostamente pré-existente a eles. 'Supostamente' porque, embora apresentados num molde de convicção e veracidade e sem nenhuma indicação subliminar que, ao nível textual ou paratextual, nos pudesse convidar à suspeita, antes porém com provas e argumentos que sustentam uma certeza baseada na aparente credibilidade das descrições dadas a ler ou ouvir, os filmes de Hitchcock e de Cronenberg dos quais nos fala Ana Teresa Pereira nunca existiram. De igual modo, a estátua da Bacante que Calístrato atribui a Escopas é de atestação incerta no conjunto das obras conhecidas ou sobreviventes do escultor e arquiteto grego, incerteza que marca a maioria das suas restantes descriptiones, bem como as transcrições dos discursos do mesmo género de sofistas anteriores, 'imitados' por ele. É apontada com insistência, na generalidade da bibliografia histórico-crítica, a impossibilidade de aferição do contacto direto (porquanto este seja afirmado e encenado) dos oradores com as obras que ofereciam depois ao público em 'reapresentações' ecfrásticas, sendo por fim consensual que boa parte da estatuária, da pintura, das personagens e das situações (mitológicas ou não) de que falaram lhes foi dada a conhecer sobretudo através de descrições 
literárias anteriores, muitas vezes com origem na poesia de tradição homérica, sem que ao longo do processo estivesse alguma vez implicada necessáriamente a realidade material dos objetos do discurso ${ }^{2}$.

$\mathrm{Na}$ verdade, a inexistência física das obras de arte descritas, referindonos aqui tanto à estátua quanto aos filmes, contrastiva com a factualidade da vida dos seus autores supostos, não constitui qualquer abuso ou incoerência à vista da retórica clássica. Pelo contrário, este seria idealmente um pressuposto da ekphrasis ou descriptio: um exercício propedêutico, que tinha por função desenvolver nos jovens retores a capacidade inventiva, a eloquência e a verosimilhança, jogando para isto com o que seria o conhecimento do mundo, isto é, a mundividência e o horizonte de expetativas, do seu auditório. Como explica João Adolfo Hansen no artigo "Categorias epidíticas da ekphrasis":

A ekphrasis é falsa fictio, pois narra o que não é; sua audiência sabe disso [...]. Como exercício de eloquência, a ekphrasis é uma pragmática: evidencia justamente a habilidade do orador que espanta a audiência com

2 Este aspeto particular da construção do género ecfrástico na Antiguidade suscita permanente inconstância e merece diferentes graus de atenção na crítica e no comentário contemporâneos. Se V. Vagenou, p. ex., não chega sequer a equacionar a questão quando considera a descrição de Calístrato da estátua de Escopas (Vagenou, 2004: §12), já V. Cunningham é peremptória tanto em relação ao juízo a (não) ter da veracidade dos poetas e romancistas modernos, quanto ao que ela parece considerar a simples inexorabilidade da écfrase como exercício literário: "These may be real, actual frescoes, statues, paintings, ruins, whatever, or they may be fictional, made-up ones. I don't think that matters all that much, either in theory or in practice. But whether real, historical items, or invented ones, the imperative that literature seems to feel to picture such nonverbal items, to incorporate them into text, to have us picture them along with the writer, the poet, the novelist and their characters, does appear to be simply inescapable" (Cunningham, 2007: 57). P. Hadot também não aborda diretamente o assunto no seu prefácio a La galerie de tableaux, muito embora insista com frequência na articulação entre realidade e reconstrução imaginária como fenómeno essencial do processo de leitura/audição da écfrase, assim como, por outro lado e da parte do sofista e retor - neste caso, Filóstrato, o Velho -, em "ce qui était réellement représenté sur les tableaux et ce qui n'était qu'amplification oratoire" (Goethe apud Hadot, in Philostrate: xx). A introdução à edição inglesa traduzida por A. Fairbanks decide-se pela ambivalência: "It is of little consequence, therefore, whether or not the Descriptions of Callistratus are based on real statues he had seen. Probably we should assume that he writes about what he had himself seen [...].At the same time, such praise as he offers to the "Opportunity" of Lysippus or the Bacchante of Scopas or the Eros of Praxiteles is by no means dependent on his personal acquaintance with these statues; indeed it rather smacks of a literary origin" (Callistratus: 372). Não é nossa intenção insistir neste ponto mais do que os especialistas o fizeram; no entanto, serve este excurso para sublinhar um dos eixos fulcrais neste estudo dos textos de Ana Teresa Pereira: a inventio enquanto elemento fundamental da matriz clássica da retórica ecfrástica, que permanece (como capacidade/potencialidade inventiva, numa aceção mais livre e recontextualizada do termo), como se verá, e com interessantes manifestações, neste exemplo pós-moderno. 
a narração da falsa fictio tornando o efeito provável porque sua imaginação é alimentada pelos topoi da memória partilhada. (86)

\section{Do verdadeiro texto falso ao falso filme verdadeiro}

No entanto, classificar os textos de Ana Teresa Pereira apenas por equivalência com esta forma original de écfrase, rigorosa e específica, quase completamente perdida na névoa que esbate na atualidade os limites do conceito, parecer-nos-ia constituir uma explicação apressada e insuficiente. É pois necessário interrogarmo-nos sobre a particularidade de a autora ter escolhido dissertar nestes 'contos' acerca de filmes que não existem como se existissem de facto, estabelecendo comparações fundamentais com filmes reais, e dos mesmos realizadores, que lhes são muito próximos: Rebecca (1940), de Hitchcock, para "Nightmare", e The Fly (1986), de Cronenberg, para "The Double".

A alternativa mais evidente seria dedicar os 'contos' precisamente a Rebecca e The Fly; mas, não sendo assim, deparamos aqui com um tipo de invenção que ultrapassa muito a "amplificação oratória" prevista nas descrições dos sofistas. Não se trata apenas de um jogo com os "topoi da memória partilhada" da audiência, o público leitor, sem dúvida aqui ainda importante, mas de um jogo com a recursividade da literatura em relação com o cinema, e com os potenciais interstícios gráficos - vasos comunicantes, ou, nas palavras de Heffernan, "energias paragonais (escrever versus 'picturing' [pôr em imagem]" (Cunningham: 71) - entre uma arte e outra; no fundo, falamos da presentificação/recriação que a descrição ecfrástica (criativa) possibilita e opera no objeto (d)escrito, dotando-o de uma (nova) vida. Para a reunião de um pequeno campo semântico desta questão em particular, vimos que Calístrato fala do "furor" e do transporte da "imitação" para a "realidade" da estátua de Escopas que ele descreve, Hansen fala de "enargeia [vividez]", Vagenou usa o termo "vivificação" e Cunningham defende "a realidade real do momento ecfrástico da ficção" . Não obstante, o caso de Ana Teresa Pereira, e dispensando totalmente o problema do verdadeiro conhecimento (empírico) do escritor do objecto real que ele descreve, leva a um outro extremo a asserção de que "[a]ll the objects of the ekphrastic gaze are made ones. Doubly so, in fact, for these objects are also re-made out of words" (Cunningham: 68), uma vez que, se podemos argumentar que pela sua qualidade de 'pastiche' pós-moderno os 'contos' aqui em análise são refeitos a partir da combinação e da reconstituição de elementos de outras fontes originais, com incidência principal nas filmografias de Hitchcock e de

3 Cf., respetivamente, Callistratus: 381, Hansen: 86 e passim, Vagenou: $\$ 11$ e Cunningham: 63 . 
Cronenberg e em vários outros 'textos' de proveniências muito diversas, é também notório que os filmes que eles encerram sejam, literalmente, apenas e ab ovo, feitos no ato da sua escrita, feitos de palavras.

Temos designado estes 'contos' entre aspas, já que a especificidade da sua natureza os desvia muito da narrativa de ficção per se, para formar um texto dúplice e amalgamante a que provisória e perifrasticamente chamaremos descrição narrativa - literária - de um medium narrativo - cinema -, com a narrativa que ele inclui em si - o 'filme' -, contando ainda com traços genológicos de ficha técnica, sinopse, argumento, cenografia, comentário e crítica de cinema.

Sendo inegável a ironia, em sentido etimológico, atribuível a estes constructos literários baseados na absoluta ficção e porém apresentados como possuindo autenticidade histórica, e a ironia, em sentido lato, que atravessa o discurso que os compõe - a retórica de um narrador indefinido (talvez a própria autora) -, detetável em parênteses como, por exemplo: “(A transcrição dos diálogos pode ter pequenas inexatidões.)" (58), cremos que o gesto de Ana Teresa Pereira almeja mais do que ser uma curiosa gag com o leitor mais informado acerca das obras dos dois realizadores, ou resultar em simples engano do leitor menos informado ou ingénuo, apoiando-se para tal no poder persuasivo que carrega a palavra escrita em regime realista. De facto, arriscamo-nos a sugerir que nenhum desses efeitos de leitura teria mais do que uma relevância mínima na hermenêutica destes textos.

Note-se que um dos fatores mais sublinhados no pensamento sobre a construção ecfrástica, quer nas suas formas originais da Antiguidade, quer nas suas configurações contemporâneas é "o efeito do real" (Barthes apud Cunningham: 62). Parece pois generalizável que a natureza eminentemente eidética do exercício visa, em termos poéticos e psicológicos, a criação de um verdadeiro tertium quid, originado na imaginação estimulada para a produção de imagens e imbuído de 'vida' na passagem da esfera logocêntrica (“emblemática" [Diderot] ${ }^{4}$ ) para a interpretativa (visionária/concretizante). É isto o que, estendendo-o a toda a poesia, Diderot identificou como "un esprit qui meut et vivifie les syllabes" (apud Hadot, in Philostrate: xvi-ii, ênfase nossa), ou o que os antigos denominaram por "furor", "inspiração",

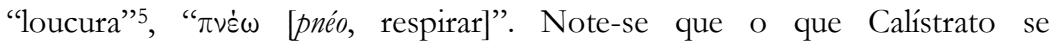
compromete a descrever é, especificamente, a "inspiração da obra de arte"

\footnotetext{
4 “'[C]'est ['esprit] qui fait que les choses sont dites et représentés tout à la fois; que dans le même temps que l'entendement les saisit, l'âme en est émue, l'imagination les voit et l'oreille les entend, et que le discours n'est plus seulement un enchaînemet de termes enérgiques qui exposent la pensée avec force et noblesse, mais que c'est un tissu d'hiéroglyphes entassés les uns sur les autres qui la peignent. Je pourrais dire, en ce sens, que toute poésie est emblématique" (D. Diderot [1875]. "Lettre sur les sourds-muets". Oeuvres Complètes. Vol. I. Paris: Assézat-Tourneux, 374, apud Hadot, in Philostrate: xvi-xvii).

${ }^{5}$ No sentido de 'possessão' pelas Musas. Sobre este terceiro tipo de loucura, sugerido por Platão como aquele que inspira os poetas, vide Philostrate: 380, Nota 2.
} 
(Callistratus: 381, \1), e não a obra de arte, simplesmente, em termos formais ou superficiais, deixando claro que o maior foco do seu interesse - e o da audiência, por sugestionamento - recai sobre esse 'sopro' vivificante e criador, de carácter demiúrgico, que fez nascer a obra, a qual pode apenas ser considerada 'obra' a partir desse estágio de reconstituição literária que está ao cargo do narrador com a dupla função de exégetes (Hansen: 86 e 101) e de poiétés, ele mesmo ‘(re)contaminado' por uma inspiração divina igual à que, na techne, o artesão transmitiu à primeira versão material do seu objeto artístico. Logo, no diferimento literário (ou na recriação por palavras), o poeta tornase, realmente, o novo criador de uma outra obra, que ele, equiparado com os deuses, dota de vida e existência próprias.

Os ensaios de filmes de Ana Teresa Pereira, estas "ficções falsas" designação que se deve entender mais como hiperbólica do que como pleonástica - para as quais ela firma autorias e urde um puzzle compositivo, só têm existência/presença, e daí a importância de os ler como paradigmas de criação poética, na verdade do texto, no microcosmo literário em que, mesmo na relação com a 'realidade real', não há uma noção de 'inverdade', isto porque a realidade já 'cedeu' muito antes, nos primórdios do impulso [pnéo] artístico, quando sentida como deceptiva por natureza e inevitávelmente transfigurada pelo processo total (hiperbólico) e contagiante que é a ficcionalização. Repare-se que, se a ficção, como ela é habitualmente entendida, seria a verdadeira fictio, podemos ler a falsa fictio de que fala Hansen, seguindo o efeito de reversão para um contrário que o adjetivo provoca, como, simplesmente, a verdade.

Não surpreende, pois, que, tanto na generalidade da bibliografia crítica quanto nos textos de retores antigos e escritores modernos, como já tivemos oportunidade de verificar, o valor da 'verdade' ecfrástica seja um tópico tão recorrente. Valentine Cunningham sublinha oportunamente a "presença, realidade, verdade do escrito", e o facto de o segmento textual de pendor ecfrástico (autorreflexivamente, acrescentamos nós), garantir -visivelmente a "existência da escrita, do que é escrito" (Cunningham: 62). Ela conclui:

All in all, then, what ekphrastic registers is the astonishing power of art to tell, convince, persuade, overwhelm, to mean strongly, to be with a transcendent force, to be a kind of truth: in other words, ekphrasis celebrates the wonder, the miracle, the shock of art, the aura of the artobject (to use Walter Benjamin's word), its thauma (to use the Iliad's word). (65)

Isto justifica a prosopopeia da voz do autor de "Nightmare", à qual Ana Teresa Pereira recorre em jeito de prova e argumento, e em abono do seu poiema, citando 'falsamente' a famosa e historicamente factual entrevista de Truffaut a Hitchcock: 
Truffaut tentou estabelecer um paralelo entre Nightmare e Rebecca. Alguns elementos são comuns - a casa isolada, a governanta e acima de tudo a atmosfera irreal, de conto de fadas. Se Rebecca é uma versão de Cinderela, Nightmare tem muito a ver com o Barba Azul e com a Bela e o Monstro. $[\ldots]$

Hitchcock acrescentou: "Sim, é uma velha história, um conto de fadas, talvez... É acima de tudo, literalmente, um pesadelo". (Pereira, 1997: 143-4)

Numa crónica coligida em O Ponto de Vista dos Demónios, a autora discorre sobre a influência de Jorge Luis Borges, recordando a importância fundamental que documentos e livros 'fictícios' têm na obra do escritor argentino, no que parece corresponder à teoria do que foi aqui anteriormente exposto como prática:

[Ele] ensinou-me que é inútil escrever romances de quinhentas páginas quando podemos escrever notas sobre livros imaginários ou escritores que não existem, que toda a arte é ficção (e no cinema todos os efeitos são especiais, como sabia Billy Wilder), que o sonho é uma parte (talvez não a menos importante) da realidade, que os livros devem escrever-se sozinhos ("Art happens", dizia Whistler), que todos os paraísos são paraísos perdidos, e que num labirinto se deve virar sempre à esquerda. $[\ldots]$

Uma vez revelou (mas só a poucos leitores, a muito poucos leitores) que a realidade começava a ceder (o certo é que desejava ceder). [...] Mas, como Borges, eu não me importo. (Pereira, 2002: 76-7)

Assim, a "cedência da realidade" (que redunda paradoxalmente na criação de realidade) não é aqui só uma literalização e um entendimento concretizado de um pressuposto do ato de leitura - o que em termos académicos se conhece por "suspension of disbelief" -, mas é também o item crítico porventura mais essencial numa abordagem teórica conteudística de "She Who Whispers" e de "O ponto de vista das gaivotas".

\section{Escrever cinema: um género intermedial}

Um dos aspectos mais inquietantes na conceção destes filmes escritos é a cadeia textual - "jeu de miroirs" - que eles têm de percorrer. É como se a 'hiper-consciência' da sua literariedade levasse a autora a investir precisamente na nesga da fronteira entre meios de representação em que é a palavra que prevalece - o que antes identifiquei metaforicamente como 'interstícios gráficos’ - para os conduzir a uma espécie de coalescência total, e, circularmente, poder até remeter para formas distantes, originais, dos textos: 
um conto da autoria do próprio David Cronenberg ("She Who Whispers"), dos tempos em que era estudante universitário ("no mesmo ano em que ganhou o Epstein Award com um outro conto" [55]), e um conto de Daphne du Maurier.

Não é difícil averiguar que Cronenberg está realmente entre os vencedores do Norma Epstein Award da University College of Toronto ("com um outro conto"), e que muito do que Daphne du Maurier escreveu se aproxima em traços gerais de "Nightmare", mas é praticamente certo que estes textos a que a autora se refere nunca tenham existido. Ou talvez existam de facto, tão-só com outra roupagem, latentes no nosso imaginário coletivo como parcelas do conhecimento do mundo da "audiência" - tal como acontece com os 'duplos' reais (Rebecca e The Fly) dos filmes inventados. Foi John Dickson Carr, por exemplo, o autor policial mais influente na obra de Ana Teresa Pereira, que publicou em 1946 um romance precisamente intitulado $\mathrm{He}$ Who Whispers, cuja trama, não por acaso, como acontece em "She Who Whispers", atribuído a Cronenberg, se desenvolve em torno do caso misterioso de um homem apunhalado pelas costas.

Repare-se que, em rigor, o palimpsesto que forma os filmes conta com pelo menos cinco camadas de texto: os contos originais atribuídos a Cronenberg e a du Maurier, os argumentos feitos a partir destes, a adaptação cinematográfica desses argumentos por Hitchcock e pelo próprio Cronenberg, as reconstituições ecfrásticas dos filmes e os contos assinados por Ana Teresa Pereira onde elas estão alojadas; e é certo que, numa leitura minuciosa e aturada, o leque se desdobraria ainda mais.

Podemos encontrar aqui um eco curioso com $A$ Volta no Parafuso, de Henry James, obra basilar no universo literário da autora, que se serve igualmente de um processo de trânsito da narrativa entre várias versões escritas, ditadas e reescritas, a partir de vários pontos de vista, que, a um tempo, reafirma sucessivamente aos olhos do leitor a existência de um texto (escrito), de um discurso narrativo ou de uma história, e compromete de todo a fidelidade desta versão a que ele tem acesso à versão original, certa ou 'verdadeira', perdida no labirinto da sua transferência ${ }^{6}$. Estamos pois perante a "frame story" e o princípio da repetição em diferimento que participam de um fenómeno de, nos termos de Shoshana Felman, "acting out" do próprio texto (Felman: 1977: 133). Daqui virá também a complexa dialética narrativa entre "pôr sob os olhos" (Hansen: 86 e passim) ou ocultar. Cunningham alerta para o ceticismo, "massively present, and naturally enough, in more recent ekphrastic writing - writing done in our modernist, and postmodernist, climate of doubting about the production of meaning" (67). Citando O Papagaio de Flaubert, de Julian Barnes, ela mostra como a busca pelo papagaio

${ }^{6}$ Ana Teresa Pereira escreveu, a partir de $A$ Volta no Parafuso, uma 'novela paralela' intitulada A Outra (Lisboa: Relógio D’Água, 2010), que recupera vários destes problemas, e que se revela particularmente complexa no que toca à proveniência da vOZ narradora. 
no romance, tal como a aproximação à pintura de Géricault, $A$ Balsa de Medusa, em A História do Mundo em Dez Capitulos e Meio, do mesmo autor, se dissolve "into unresolved questions, mysteries, silences, negatives, gaps, aporias, disappearances" (Ibid.).

Esta impossibilidade do conhecimento/visionamento total daquilo que está a ser mostrado é um dos tópicos mais relevantes nos contos aqui em análise. Em "She Who Whispers", lemos, por exemplo:

Martin Scorsese comentou a respeito de David Cronenberg: "ele não sabe de que tratam realmente os seus filmes." Ao que este respondeu mais tarde: "I hope I don't." (55)

O cineasta que afirmou que o seu desejo era "to show the unshowable, speak the unspeakable", explora os recantos mais obscuros do ser humano. (62)

Como na visão dos psicóticos graves, o mundo desagrega-se. (63)

Em "O ponto de vista das gaivotas" é explorado um efeito de miopia através da confusão, da confluência e da incerteza do visionado:

[U]ma mão pousa no seu ombro e ela volta-se soltando um pequeno grito [e não se diz de quem é a mão]. [...] Quando vemos a casa há sempre nevoeiro (nevoeiro que existe mesmo dentro da torre. (140)

[Q]uando as vemos de longe é fácil confundir uma com a outra. [...] Quando o homem se volta, o rosto é o que conhecemos. E ao mesmo tempo é outro... (141)

Até que chegamos à cascata final de interrogações e à absoluta 'indecidibilidade':

Mas um pesadelo de quem? [...]

Porque nem sabemos claramente quantas personagens tem a história. [...]

Qual dos dois sonha? [...]

[T]alvez duas [personagens] possam ser uma só. [...]

Talvez só exista um sonhador. [...]

Ou talvez não exista ninguém. (144)

Por outro lado, a novela de James, com a sua componente sobrenatural, pode ajudar-nos a fazer a ponte com o traço taumatúrgico que Cunningham associou à descrição "celebrativa" do objeto artístico. Da parte de Ana Teresa Pereira, o nexo é preponderante: 
O conto She Who Whispers confirma que o seu universo [o de Cronenberg] tem origem no maravilhoso, no fantasmagórico, enfim, no fantástico. (56)

No segundo caso, temos a fairy tale de "O ponto de vista das gaivotas". Aqui, o filme é Nightmare, de Alfred Hitchcock, e encontramos o par Ingrid Bergman e Humphrey Bogart a contracenar no papel de personagens que se desdobram terrivelmente, "uma casa onde há sempre nevoeiro", "o mar", "uma torre", e "a governanta, a bruxa má" (140-141), ao que sobram as comparações com $A$ Bela e o Monstro, os contos de fadas e o pesadelo.

Cunningham não hesita, e sem explicações adicionais, em utilizar a expressão "ekphrastic mode" (58) aplicada à literatura da contemporaneidade, isto é, o ecfrástico como modo transversal aos media de representação e superlativo do género; embora venha a identificar depois a écfrase, isoladamente, como "an intertextual, intermedial genre: loose; shifting over time; merging, of course, into the discourses of art history, and the textuality of anthropology and cultural studies" (60). Não nos deteremos aqui na ambiguidade destas designações; porém, não deixa de ser altamente desafiador que, entendidos como textos intermediais, os 'contos' de Ana Teresa Pereira elaborem sobre uma fusão de formas de representação tão distintas semioticamente: a apresentação fílmica de imagens e a evocação literária por vocábulos. Os filmes escritos são, pois - numa afirmação que se poderia alargar aos restantes exemplos de écfrase a que nos temos referido -, tanto produtos como produtores de tensão e enlace entre "narração e mostração", categorias entendidas num primeiro momento como modalmente opostas e, por norma, inconciliáveis 7 .

Podíamos mesmo encontrar um contra-senso tautológico na atribuição de enargeia ao que, naturalmente, já a tem: a imagem cinematográfica, com movimento, tempo e som, radicalmente evoluída em relação à pintura ou à escultura (mesmo quando se fala das "action-statues" do princípio do período clássico [Vagenou: \$12]) que os sofistas se ocuparam a 'vivificar'. No entanto, é importante perceber que, sob o disfarce da recuperação de uma imagem pré-existente, o encadeamento frásico da descrição está na verdade a projetar o filme, pela primeira vez a cada nova leitura, através da nossa imaginação - que significa neste caso, literalmente, 'formação de imagens mentais':

As primeiras imagens do filme, depois do perturbante genérico em que seres irreconhecíveis se movem numa cama (como fetos num útero?) são a preto e branco. (57)

7 Para um estudo aprofundado deste binómio e das problemáticas que ele gera, especificamente na relação entre literatura e cinema, vide A. Gaudreault, From Plato do Lumière, 2009. 
No plano inicial há uma igreja e uma pequena multidão que esconde parcialmente os noivos que acabaram de sair. Destaca-se a figura de Alfred Hitchcock com uma máquina fotográfica. [...]

O plano seguinte mostra-nos uma mão segurando uma fotografia. (140)

Bogart passa pela governanta sem a ver. A câmara segue-o num longo travelling pelos corredores sombrios (é a primeira vez que vislumbramos as entranhas da casa. $[\ldots]$

E o filme termina com o vulto cansado de um homem que sobe a escada de caracol. Depois, a casa vista do exterior. As ondas. Um grande plano das flores brancas que crescem nos rochedos. (143)

O recurso ao jargão cinematográfico só contribui para a explicitação da analogia pretendida entre a decifração e a projeção mental das imagens verbais - ou, recuperando Diderot, dos "emblemas" -, veiculando-lhes a visualidade que naturalmente não têm, e o próprio funcionamento do dispositivo fílmico, entendidos como equivalentes. À luz desta ideia, ganha redobrado sentido a insistência nas ideias de "alucinação", "sonho" e "pesadelo" em "Nightmare" e "The Double"; porque é isso que eles são, como já dissera Ana Teresa Pereira através da voz do fantasma de Hitchcock: "literalmente, um pesadelo", isto é, um atemorizador plano-sequência mental.

Pavle Levi refere-se a um fenómeno marcante de alguns movimentos de vanguarda do início do século XX como "remediação retrógrada", reportando-se ao facto de artes mais longevas, nomeadamente a literatura, replicarem e tentarem incorporar na sua estrutura formas e elementos advindos de artes novas, devedoras da inovação tecnológica, nomeadamente o cinema, e cita Walter Benjamin na argumentação sobre este constante "desejo de uma nova forma" na "era da reprodutibilidade técnica" (Levi 2012: 43). Ele avança depois no sentido da consolidação teórica dos géneros do "paper movie" e do "filme escrito":

The author conceived and designated the text as a "film scenario", yet it was never intended to be made into an actual film. [It] was, and forever remained, a "paper movie". The space it occupies is to be located somewhere between literature and cinematography: a generic hybrid, [...] neither a "rounded", self-enclosed literary work nor a film scenario proper (in the sense of representing a stage in the process of filmmaking). (46)

"[W]ritten film" seems like a format particularly suited for turning psychic automatism into a cinematic practice. Image production becomes thus a major function of the spectatorial activity which, oscillating between the private screen of one's fantasy and the objectively given "ekphrastic coordinates" of the scenaristic blueprint. (55) 
Sublinhamos aqui a ideia de "atividade espetatorial" em relação ao texto escrito, tão essencial para aquelas formas textuais específicas praticadas pelos autores de vanguarda, como para "O ponto de vista das gaivotas" e "She Who Whispers", de Ana Teresa Pereira, e que se pode traduzir por uma leitura de ação da qual eles dependem, ou seja, não uma leitura que os idealize ou 'interprete' em termos conceptuais, mas uma leitura que, contando com a participação coadjuvante do leitor como produtor de imagens, os 'performatize', e os realize num mundo.

$\mathrm{O}$ retorno à natureza (sinónimo de realidade), fora desde sempre o primeiro objetivo da mimesis levada a cabo pelos autores de écfrases. Calístrato revela ao auditório a carne da estátua de Escopas, o tom da sua pele e o esvoaçar das suas vestes, e relata com entusiasmo a beleza e o furor da sua dança báquica. E também Ana Teresa Pereira, nos limites do seu artifício e confrontada com ele, vai desembocar na natureza; uma natureza mínima, de estúdio e de cartão, mas, ao olhar do poeta e do leitor ativo, não há distinção entre essa e outra; a maqueta não inviabiliza de maneira nenhuma a verdade das flores, se é ela que, no poiema, lhas dá:

Um sonho sem sonhador.

Quase o vazio.

Uma simples maqueta.

O mar.

Gaivotas.

$\mathrm{E}$ as flores brancas que crescem entre os rochedos. (144)

Numa entrada de dicionário dedicada ao pós-modernismo, Hendrik van Gorp declara:

Ao autor pós-moderno [...] perdido no labirinto de uma imensa biblioteca, não resta mais do que copiar os textos anteriores, citá-los, fazê-los dialogar entre si [...], multiplicando os espelhos, ele torna problemática a própria noção de texto. (Gorp 2005: 384, tradução nossa)

Em seguida, oferece os exemplos de Umberto Eco e Jorge Luis Borges aquele que foi, no início, o professor destas falsas ficções. Mas é a "problemática noção de texto" que, concluindo, gostaríamos de reter. A multiplicação dos espelhos surge como o grande busílis do pós-modernismo e, por inclusão, dos textos de Ana Teresa Pereira aqui em análise, presos numa forma dúbia e algo inclassificável entre a literatura e cinematografia, manifestações de uma palavra constantemente dêitica, e, em sentido bíblico, instauradora. Por isso mesmo, e segundo Orson Welles, "o que conta é a poesia"; e isso convida-nos, ao ponderar sobre estes 'contos' e os seus efeitos de leitura, a citar um poeta que defendeu que "cada poema, / no seu perfil / 
incerto / caligráfico, / já sonha / outra forma"8. É na operação desse sonho que estes filmes se fazem.

\section{Referências}

CALLISTRATUS (1981). "Descriptions", Philostratus the Elder, Imagines; Philostratus the Younger, Imagines; Callistratus, Descriptions. Trans. Arthur Fairbanks. The Loeb Classical Library, ed. T. E. Page et al. London: William Heinemann.

CUNNINGHAM, Valentine (2007). "Why Ekphrasis? ”. Classical Philology. Vol. 102. N. 1 (Special Issue on Ekphrasis, ed. Shady Bartsch, Jaś Elsner): 57-71.

FELMAN, Shoshana (1982). "Turning the Screw of Interpretation". Literature and Psychoanalysis. The Question of Reading: Otherwise, ed. Shoshana Felman. Baltimore/London: The John Hopkins University Press. 94207.

GAUDREAULT, André (2009). From Plato to Lumière: Narration and Monstration in Literature and Cinema. Trans. Timothy Barnard. Toronto: University of Toronto Press.

GORP, Hendrik van et al. (2005). "Postmodernism". Dictionnaire des Termes Littéraires. Paris: Honoré Champion. 383-384.

HANSEN, João Adolfo (2006). "Categorias epidíticas da ekphrasis". Revista USP, N. ${ }^{\circ} 71: 85-205$.

LEVI, Pavle (2012). Cinema by Other Means. New York: Oxford University Press. PEREIRA, Ana Teresa (1997). A Coisa Que Eu Sou. Lisboa: Relógio D’Água. Relógio D’Água. 75-77. (1997). "O tigre". O Ponto de Vista dos Demónios. Lisboa:

PHILOSTRATE (1991). La Galerie de Tableaux. Trans. Auguste Bougot. Paris: Les Belles Lettres.

VAGENOU, Vassiliki (2004). "The Greek 'mobile' statue: Myth and Realities”. ANISTORITON: ArtHistory, Vol. 8, Dezembro 2004. Web. 28 de Agosto de 2013. http://www.anistor.gr/english/enback/o044.htm

\section{Financiamento}

Artigo produzido no âmbito do projeto de investigação "Falso Movimento Estudos sobre Escrita e Cinema” (referência PTDC/CLE-LLI/120211/2010), Centro de Estudos Comparatistas da Faculdade de Letras da Universidade de Lisboa, financiado pela FCT - Fundação para a Ciência e a Tecnologia.

(C) 2013 Amândio Pereira Reis.

8 Cf. Carlos de Oliveira, "Lavoisier", Trabalho Poético, Lisboa: Assírio \& Alvim, 2003, p. 201, vv. 7-12. 